\title{
Physical experiments of land subsidence within a maar crater: insights for porosity variations and fracture localization
}

\author{
M. Cerca ${ }^{1}$, L. Rocha ${ }^{2}$, D. Carreón-Freyre ${ }^{1}$, and J. Aranda ${ }^{1}$ \\ ${ }^{1}$ Centro de Geociencias, Universidad Nacional Autónoma de México, Campus Juriquilla, Querétaro, Qro., \\ 76230, México \\ ${ }^{2}$ Posgrado en Ciencias de la Tierra, Centro de Geociencias, Universidad Nacional Autónoma de México, \\ Campus Juriquilla, Querétaro, Qro., 76230, México
}

Correspondence to: M. Cerca (mcerca@geociencias.unam.mx)

Published: 12 November 2015

\begin{abstract}
We present the results of a series of physical models aiming to reproduce rapid subsidence (at least $25 \mathrm{~m}$ in 30 years) observed in the sediments of a maar crater caused by extraction of groundwater in the interconnected adjacent aquifer. The model considered plausible variations in the geometry of the crater basement and the measured rate of groundwater extraction ( $1 \mathrm{~m}$ per year in the time interval from 2005 to 2011) in 15 wells located around the structure. The experiments were built within a rigid plastic bowl in which the sediments and rocks of the maar sequence were modeled using different materials: (a) plasticine for the rigid country rock, (b) gravel for the fractured country rock forming the diatreme fill and, (c) water saturated hollow glass microbeads for the lacustrine sedimentary fill of the crater. Water table was maintained initially at the surface of the sediments and then was allowed to flow through a hole made at the base of the rigid bowl. Water extraction provoked a sequence of gentle deformation, fracturing, and faulting of the surface in all the experiments. Vertical as well as lateral displacements were observed in the surface of the experiments. We discuss the results of 2 representative models. The model results reproduced the main geometry of the ring faults affecting the crater sediments and helps to explain the diversity of structures observed in relation with the diatreme geometry. The surface of the models was monitored continuously with an optical interferometric technique called structured light projection. Images collected at nearly constant time intervals were analyzed using the ZEBRA software and the obtained interferometric pairs permitted to analyze the full field subsidence in the model (submilimetric vertical displacements). The experiments were conducted at a continuous flow rate extraction and show a also a linear subsidence rate. Comparison among the results of the physical models and the fault system associated to subsidence in the maar show that fault geometry in the sedimentary sequence imitates closely the geometry of the volcanic basement.
\end{abstract}

\section{Introduction}

Rincón de Parangueo is a Quaternary volcanic maar, a crater formed by a phreatomagmatic eruption, located in the northern portion of the Michoacán-Guanajuato volcanic field in the central sector of the Trans Mexican Volcanic Belt (Fig. 1, location of the maar: $\left.20^{\circ} 25.839^{\prime} \mathrm{N},-101^{\circ} 14.917^{\prime} \mathrm{W}\right)$. Volcanic maars are craters located above a feeder magmatic dike that poses into contact magma with groundwater causing a gaseous explosion and resulting in a rock filled fracture with a conic shape, called diatrema (Lorenz, 1986). Although the literature on maars is extensive the studies of post-eruption subsidence in the lacustrine sequences filling the craters are rare (e.g., Suhr et al., 2006; Pirrung et al., 2008). Rincón de Parangueo was one of four maar craters nearby the locality of Valle de Santiago village that used to have a perennial lake and nowadays is partially occupied by a brine lake. During the 1980's progressive desiccation began as a consequence of water overdraft from the regional aquifer that used to feed the lake (Escolero-Fuentes and Alcocer-Duran, 2004; 


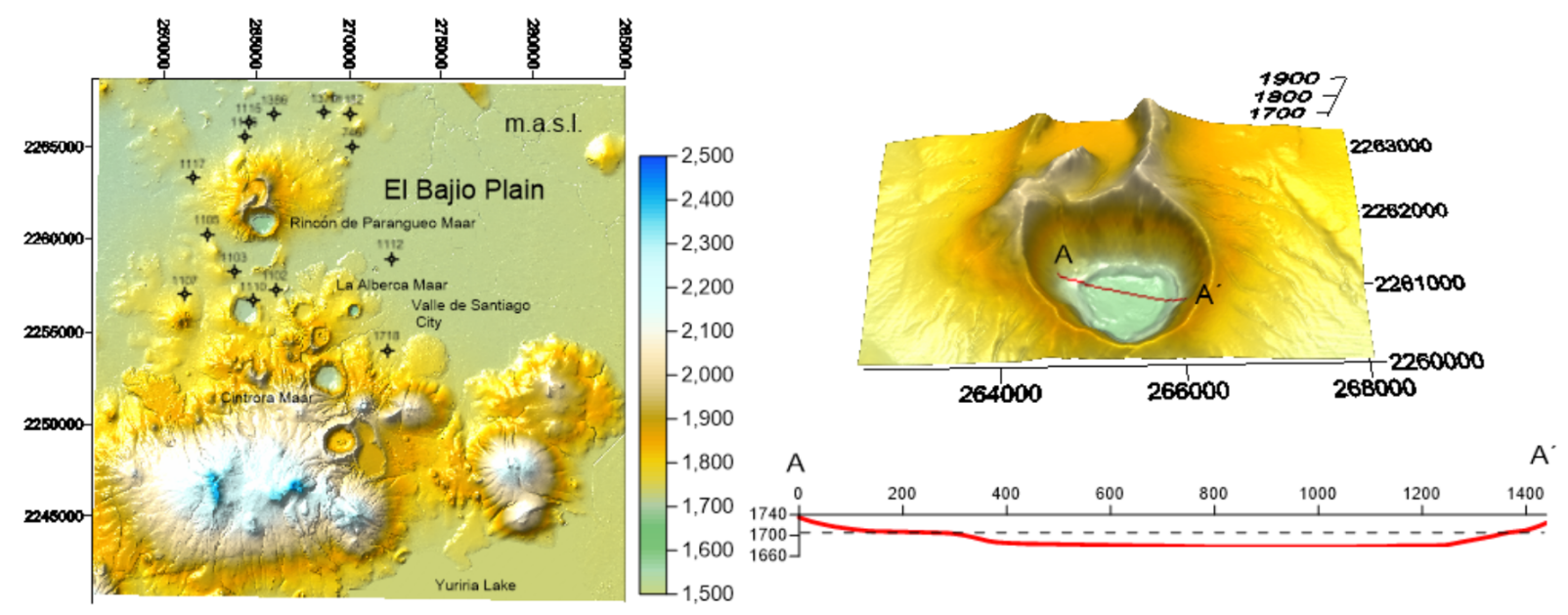

Figure 1. Digital elevation model obtained by LIDAR data from INEGI (Institute of Informatics and Geography; Mexico) showing the volcanic cluster in the area of Rincón de Parangueo maar. Perspective view of the crater and the annular fault system affecting the bottom. Topographic profile crossing the crater showing the initial lake surface (dashed line) and the present day leveling (red line).

Aranda-Gómez et al., 2013). Detailed geologic mapping in the sediments of the lake bed shows clear evidence of rapid active subsidence contemporaneous to desiccation (ArandaGómez et al., 2010, 2013; Aranda-Gómez and CarrascoNuñez, 2014; Cerca et al., 2014). Deformation is characterized by a main ring-shaped normal fault accompanied by gravitational sliding and gliding of mud blocks, and folding at the foot of the slides. Sinking of the maar crater is associated with the formation of vertical fractures and lateral mass movements to the depocenter, resulting in the formation of tensile fractures. Likewise, normal faulting exerts a major influence in the location of today depocenter.

Sinking at the bottom of the crater produced a ring-fault system which is exposed near the former coast of the lake, on a pair of parallel $15 \mathrm{~m}$ high topographic scarps. Attitudes of laminations in the mud exposed in the scarp are consistent with down sagging of the sediment caused by sinking of the lake's depocenter. Tilt angles of the laminations vary between 10 and $35^{\circ}$ towards the basin. Normal faults exposed at the topographic scarp produced in some areas deformation domains that are consistent with the presence of listric detachment structures, which produced rollover anticlines with axes located near the former coast of the lake. Lake sediments are composed by a sequence presenting rhythmic layering with changes of colors between beige and dark brown; beige layers are composed carbonate micritic mud with crystals of $2-5 \mu \mathrm{m}$ (Kienel et al., 2009). The dark brown layers are composed by clay, silt, and organic material. Also interbedded can be observed more prominent layers with black coloration constituted mainly silt and fine sand. In cores, the lower part of the observed sequence is composed of deformed layers affected by fractures with a small displacements. Mechanically, the whole sequence is characterized by low compressible silty sediments, and the gravimetric water content increases gradually with depth up to more than $40 \%$.

Water withdrawal in the aquifer system adjacent to the volcanic field has been pointed out as the cause for deformation and desiccation of the lake since the 1980's decade (Escolero-Fuentes and Alcocer-Duran, 2004; Aranda-Gómez et al., 2013; and references therein). Fragmentation of the country rock due to diatreme formation is likely to be contained within the maar-diatreme and less likely to propagate down to deeper levels into the feeder dike. Nevertheless, alignment and overlap of the numerous craters at the study area indicates the presence in the subsurface of multiple parallel and orthogonal feeding dykes. Coalescence of the shallow structures suggested by vent distribution might be the cause of a high hydraulic connectivity below the volcanic edifices with the regional aquifer. Faults and fractures within the country rock enhance the hydraulic conductivity and might serve as drainage lines into the regional aquifer system. Thus, the maar may be divided into two significant hydrogeological units, a deforming lacustrine sedimentary unit, acting as an aquitard and, the high fractured diatreme hydraulically connected with the regional aquifer system. Nowadays groundwater extraction and evaporation exceed the inflow of groundwater into the crater. Therefore, the bottom of the crater will either be dry except for runoff from precipitation or develop into a brine lake where accumulation of salts will take place in the depocenter. The drawdown of the groundwater table will continue indefinitely because the region depends on groundwater for human consumption.

The present day elevation at the bottom of the crater (1868 m a.s.1.) is lower than the adjacent Bajio plain (1710$1730 \mathrm{~m}$ a.s.l). The variations in the piezometric levels were recorded by the National Water Commission (CNA) in selected wells around the Parangueo maar for the time period 


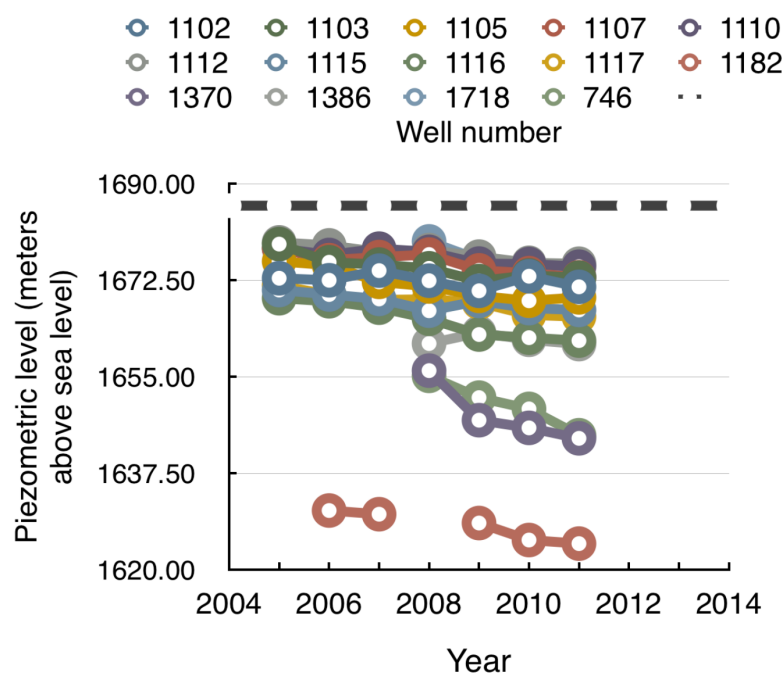

Figure 2. Piezometric level evolution for the time interval between 2005 and 2011 for selected extraction wells measured around the Rincón de Parangueo maar. Location of the wells is indicated in Fig. 1.

between 2005 and 2011. The observations were made twice in a year at both dry and raining seasons, we present here the measurements made during the dry season (Fig. 2). All piezometers record a similar depleting evolution of $1 \mathrm{~m}$ per year, but the cluster of wells 1370, 1182 and 746, located northeast of the Rincón de Parangueo maar record a deeper piezometric level. In summary, the piezometric data suggest an significant hydraulic gradient towards the northeast and the data can be interpolated to a lineal decrease in the water table for the last 30 years. In this work we aim at reproducing the subsidence observed in the Rincón de Parangueo maar by constructing a series of scaled physical models.

\section{Experimental subsidence bowl}

Experiments were conducted using a plastic bowl simulating the overall half-sphere shape of the maar crater. Plasticine was used to mold and vary systematically the different geometries of volcanic basement (rigid country rock) assumed to be below the sedimentary sequence. Variations in the geometry included ring circular faults, ring square faults, parallel faults, and asymmetric basement (Fig. 3). The internal part of the bowl was filled with gravel to simulate the highly fractured country rock in the volcanic conduct. Posteriorly, the bowl was filled up to an horizontal level with a fine grain size and well sorted, slightly cohesive granular media (hollow glass microbeads) completely saturated in water, simulating the initial conditions of the lake maar in the 1980's when the phreatic level reached the surface. In nature, porosity changes during subsidence are related to effective stresses. The water head decrease in the maar was of about $30 \mathrm{~m}$ in the last 35 years. For scaling we have measured
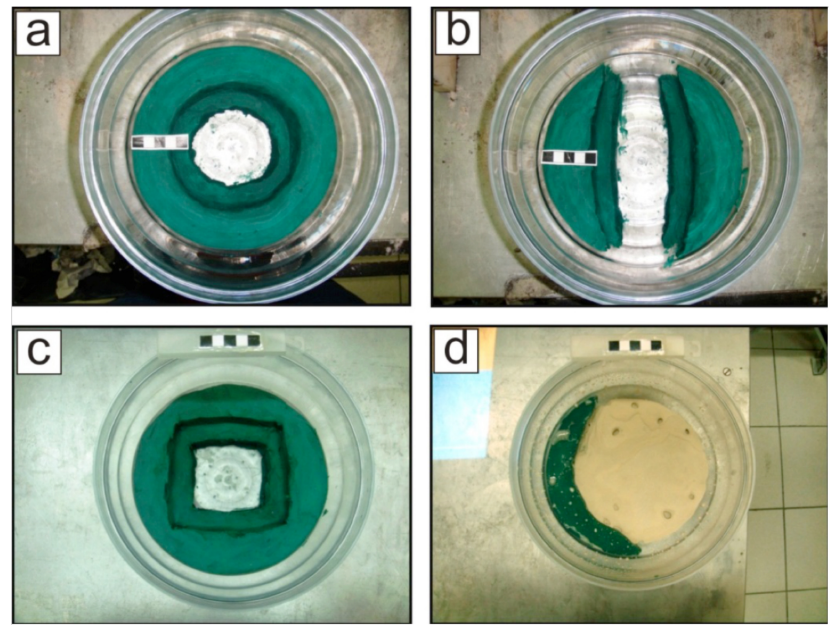

Figure 3. Photographs of the experimental setup showing the plasticine molded to produce variations in the geometry of the rigid country rock. The bowl was then filled to the level of the plasticine with gravel and covered with hollow glass microbeads to obtain a plain surface. (a) Ring faults circular, (b) parallel faults simulating a magmatic dike shape, (c) ring faults square, (d) asymmetric faults set up.

porosity of samples and assumed the initial porosity. Experiments are a simplification of nature and assume that: (1) the lacustrine material is relatively homogeneous, (2) the voids of the lacustrine sediments are filled with water below the piezometric surface and, (3) changes in the effective stress produced by the drop of piezometric level are the main cause for the subsidence in the crater maar. The water table is also assumed to be parallel to the surface of the lacustrine sediments at the beginning of the process in nature and in the model

$\Delta \sigma_{\mathrm{ef}}^{*}=\frac{\Delta \sigma_{\mathrm{ef}} \text { model }}{\Delta \sigma_{\mathrm{ef}} \text { nature }}$,

where $\sigma_{\text {ef }}$ is the change in the effective stress and $\sigma_{\text {ef }}^{*}$ is the relation among the variations in the effective stresses in model and nature, in this case the dimensionless scaling ratio is of the order of $5.33 \times 10^{-4}$. If the total stress is constant through time the differences in the effective stresses are related to the pore pressure drop, which in turn is proportional to the change in the groundwater level.

The experimental time for all models was about $20 \mathrm{~min}$ with a flow rate maintained constant at $1.57 \times 10^{-7} \mathrm{~m}^{3} \mathrm{~s}^{-1}$ that was induced by opening of a $2 \mathrm{~mm}$ in diameter tube at the base of the bowl. Subsidence in the physical models was monitored at constant time intervals of $15 \mathrm{~s}$ using an optical system that allows obtaining subtle changes (submilimetric) in the experimental relief using the ZEBRA software (based on the work by Barrientos et al., 2008). A structured light (black and white fringes) pattern was projected on the surface of the model and the digital images recorded by a CCD sensor. Comparison between pairs of images (deformed state 

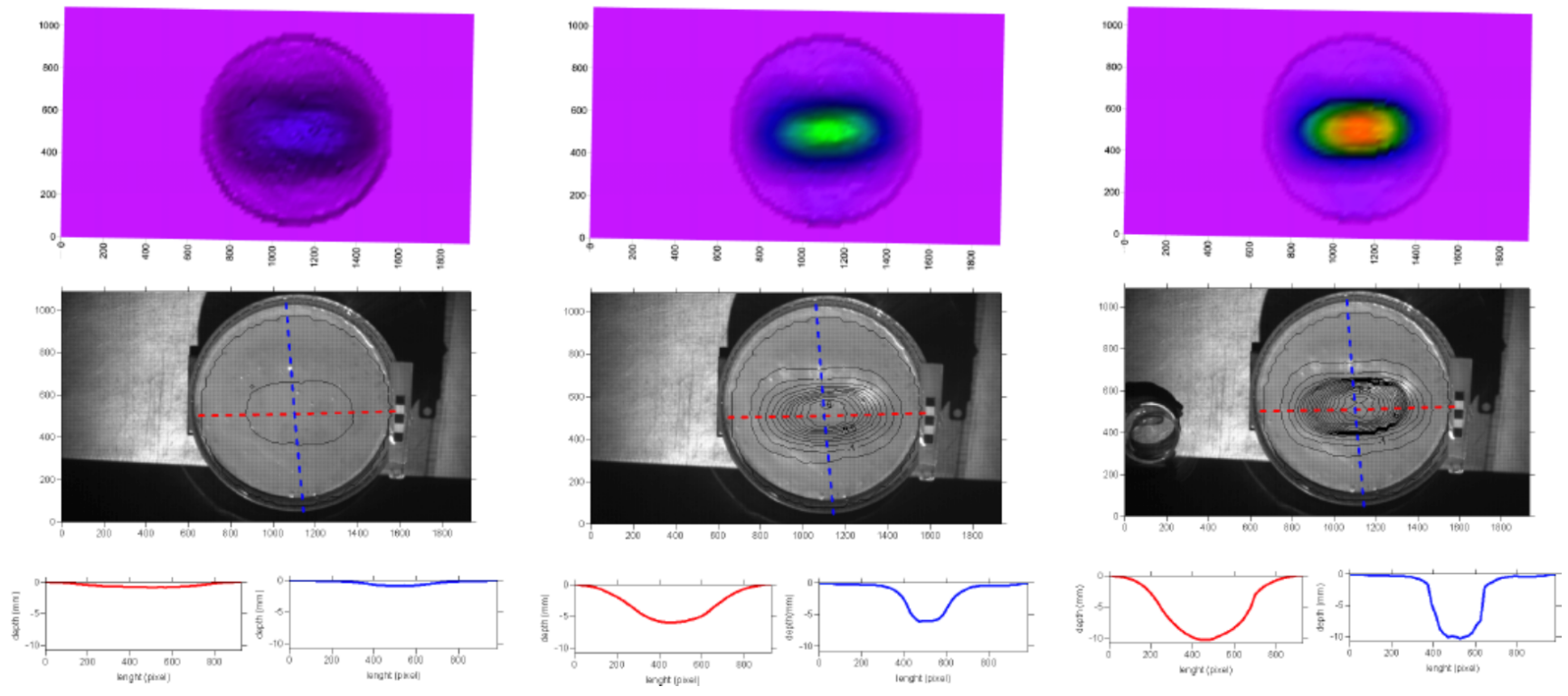

Figure 4. Example of the model results at the start, middle and end of the experiment. The images show the digital elevation model obtained with the ZEBRA software, a photograph of the model with overlapped contours and the topographic profile obtained in two orthogonal directions.

and reference image) were analyzed by the ZEBRA software using optical interferometric methods.

\section{Results}

All of the experimental runs showed a comparable evolution: (a) formation of an initial gentle depression without fracture formation in the central part of the bowl at the beginning of the water level decrease; (b) nucleation of small and isolated fractures after $5 \mathrm{~min}$ of the experiment run; (c) fracture coalescence to form a continuous ring fault with a geometry similar to the basement; (d) propagation of the fractures toward the external and/or internal part of the model. Differences in the model results depended mainly on the geometry of the diatreme.

Here, we discuss the results of two representative experiments. The first experiment discussed was of the type $b$ in Fig. 3, parallel faults representing a diatreme with the shape of a dike. A central elliptical depression formed in the first $5 \mathrm{~min}$, after $6 \mathrm{~min}$ of flow the parallel faults formed at the surface of the model. At minute 9 the parallel faults linked to form the ring fault with an elliptical shape. After $13 \mathrm{~min}$ the model ended its deformation; nevertheless some images were recorded after $30 \mathrm{~min}$ to corroborate that there was no further deformation. Figure 4 represents the evolution of the experiment in the digital elevation model, photographs with contour levels, and two topographic profiles obtained from the DEM's.

Subtle changes in the subsidence rate and geometry can be analyzed in the topographic profiles that were constructed using 25 images processed against a reference image of the initial experimental conditions. Figure 5 shows differences in the evolution of subsidence in the profile parallel to the basement faults (RED) and the profile orthogonal to the parallel faults (BLUE). Localization of deformation occurs in the BLUE profile at an earlier time (500 s) and differences in compaction are attributable to the presence of the rigid basement and thinner sedimentary deposits. The inset of Fig. 5 (RED) shows the subsidence model obtained for the center of the model that follows a nearly lineal behavior.

The second experiment was designed to explore experimentally the influence of an asymmetric basement and the influence of tilted surfaces that could act as detachment planes during subsidence. The setup considered the structural differences observed in the crater (Aranda-Gómez and CarrascoNuñez, 2014; Cerca et al., 2014), mainly the formation of rollover folds along listric fault surfaces and the formation of shortening domes. This deformational features suggest an important lateral spreading of the lacustrine sequences during subsidence. Another experimental difference was that the second sedimentary layer was thicker than in other model runs. The overall evolution of the model was similar to the first experiment, but in this case the lateral sliding of the material formed extensional fractures in a zone of the ring fault and small folds toward the depocenter, implying that lateral displacements are important to accommodate deformation. Figure 6 shows a photographic sequence of the second experimental setup, the ellipse indicates the zone of folding and the nucleation of the fractures; as well as the initial depression formed.

Obtaining an accurate digital elevation model of the experiments allowed to perform further analysis of the data. 

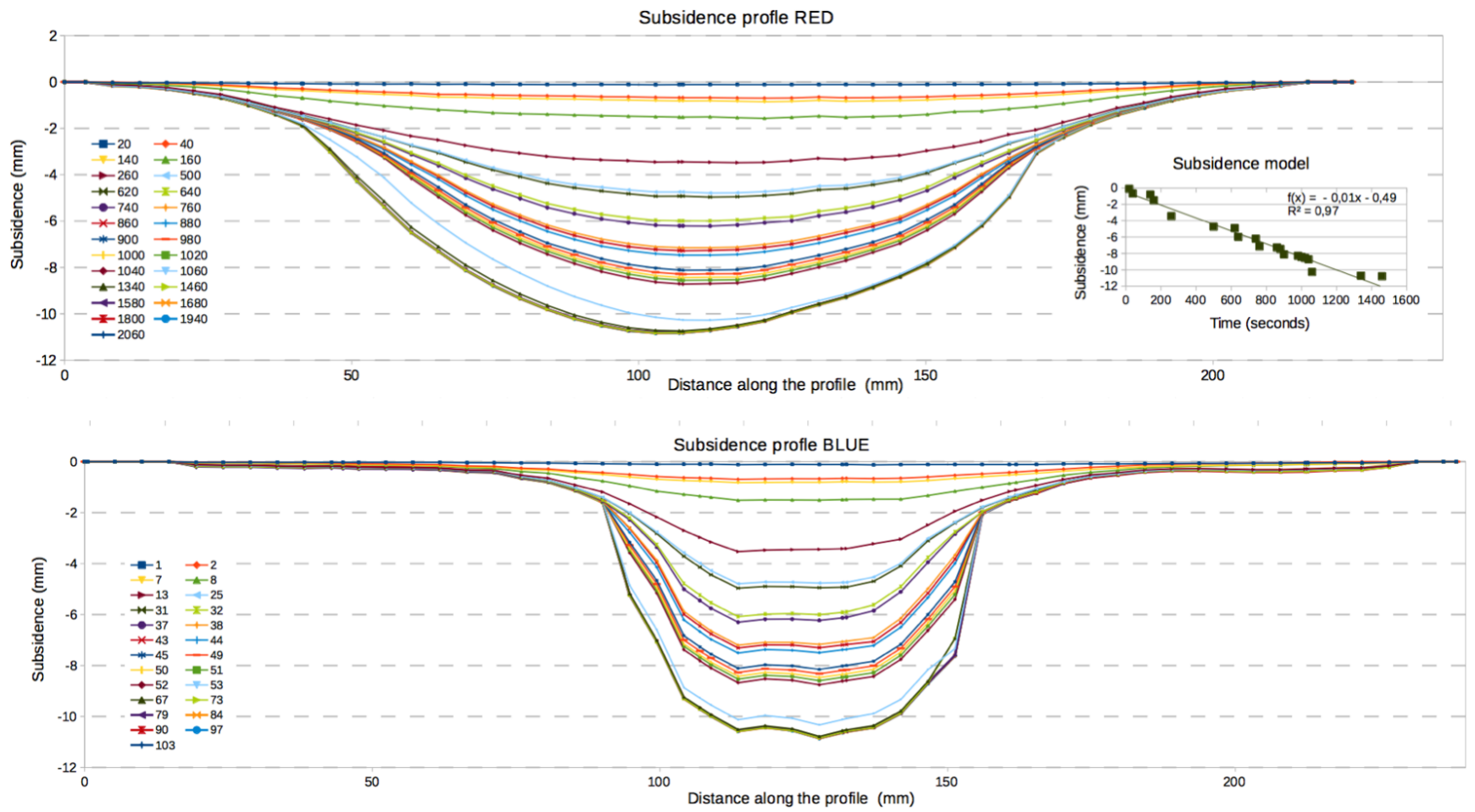

Figure 5. Topographic profiles obtained in the model in the direction: (a) parallel to the basement faults (RED) and, (b) the profile orthogonal to the parallel faults (BLUE).
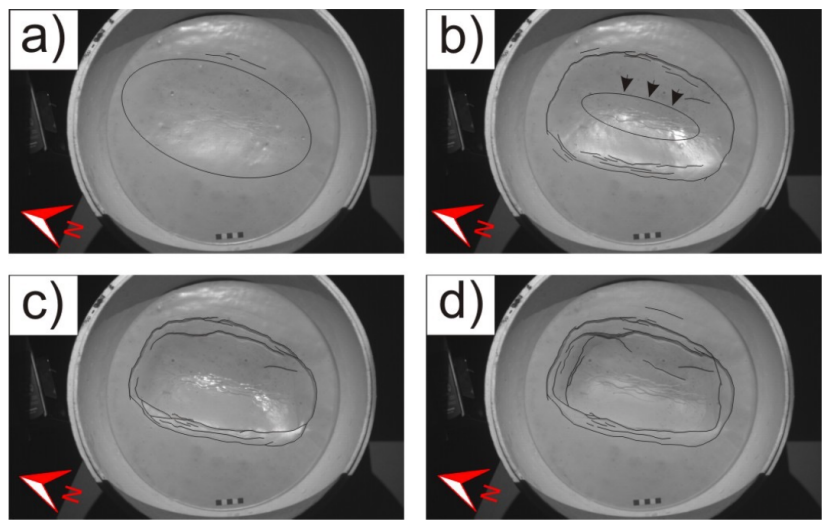

Figure 6. Photographic sequence of the second experiment showing the stages of deformation observed during desiccation of the model crater: (a) formation of a depression, (b) formation of fractures at the border of the depression and the displacement of material toward the depocenter, (c) growing and coalescence of faults, (d) desiccation of the model and formation of shortening structures in the depocenter.

For instance, the development of slopes after desiccation of the crater is important for the formation of extensional structures. In Fig. 7 we show the analysis of the subsidence and slope development of the images $\mathrm{c}$ and $\mathrm{d}$ of Fig. 6. The opening of the fractures and the formation of small folding along the axis of the elliptical depression suggest lateral spreading of the sediments in the late stages of deformation.

The comparison of model results with the deformation observed in the Rincón de Parangueo maar suggest that faults formed above the geometric borders of the rigid country rock. The ring fault pattern of faults in the mar suggest that the diatreme has a non uniform circular geometry. The presence of at least two major fault scarps in nature may indicate that the diatreme has two fault steps in the country rock.

\section{Conclusion}

Subsidence in the experiments formed patterns directly related to the geometry of the rigid country rock modeled below the sedimentary cover. Thus varying systematically the geometry of the diatreme and analyzing the results give important insights on the evolution of deformational features associated with land subsidence. Fractures and faults formed nearly above the border of the rigid basement, its position depending on the inclination of the border. The subsidence that can be generated in a crater is directly proportional to the thickness of the sedimentary lacustrine sequence. Groundwater extraction in the regional aquifer may trigger the deformation and needs to be regulated for a sustainable management of the crater lake. Finally, scaled physical experiments provided an important tool for understanding of subsidence mechanisms, for testing hypothesis of the causes of defor- 

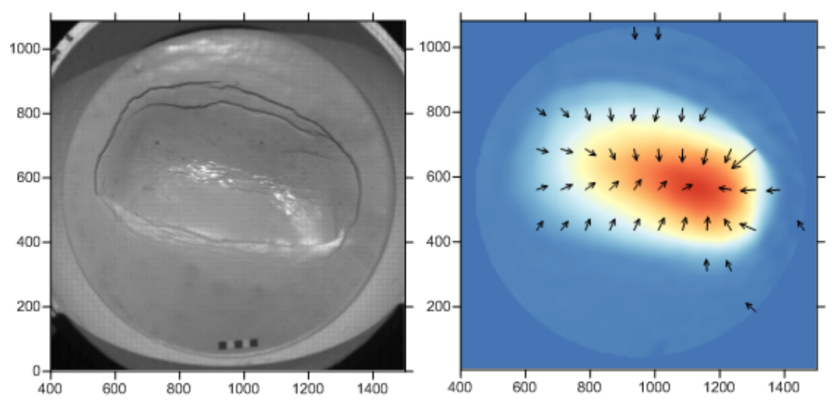

A
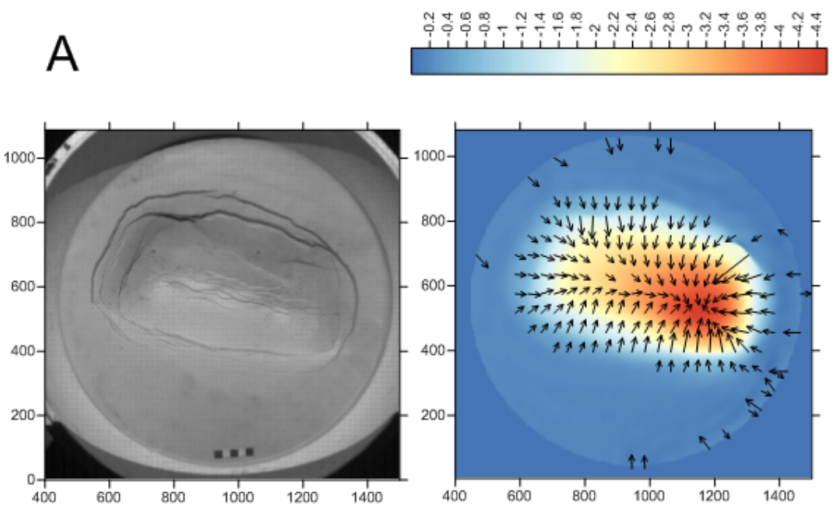

B

Figure 7. Interferometry analysis of selected photographs from Fig. 6 (c-growing of faults and d-dessication). (a) DEM of the image at the moment when the water level reached the bottom of the crater, color scale represent the subsidence in centimeters and the arrows indicate the magnitud and direction of the slope, the inplane scale is in pixels. (b) DEM of the image at a later desiccation time and deformation (color scale and arrows as above), note that the development of faulting has an effect in slope.

mation of the terrestrial surface, and for the development of monitoring techniques.

Acknowledgements. Ricardo Carrizosa of the Laboratorio de Mecánica de Geosistemas (LAMG) is thanked for his help with the experimental setup.

\section{References}

Aranda-Gómez, J. J. and Carrasco-Nuñez, G.: The Valle de Santiago maars, México: the record of magma-water fluctuations during the formation of a basaltic maar (La Alberca) and active postdesiccation subsidence at the bottom of a maar lake (Rincón de Parangueo): Intra-conference field trip guidebook, 5th International Maar Conference, 17-22 November, Centro de Geociencias, Universidad Nacional Autónoma de México, Querétaro, México, 30 pp., 2014.

Aranda-Gómez, J. J., Levresse, G., Pacheco-Martínez, J., RamosLeal, J. A., Carrasco-Núñez, G., Chacón-Baca, E., GonzálezNaranjo, G., Chávez-Cabello, G., Vega-González, M., OrigelGutiérrez, G., and Noyola-Medrano, C.: Active subsidence at

the bottom of a recently desiccated crater-lake and its environmental impact: Rincón de Parangueo, Guanajuato, México: Field trip guidebook, Eighth International Symposium on Land Subsidence, Universidad Nacional Autónoma de México, Centro de Geociencias, Querétaro, Qro., México, 1-48, 2010.

Aranda-Gómez, J. J., Levresse, G., Pacheco-Martínez, J., RamosLeal, J. A., Carrasco-Nuñez, G., Chacón-Baca, E., GonzálezNaranjo, G. A., Chávez-Cabello, G., Vega-González, M., Origel, G., and Noyola-Medrano, C.: Active sinking at the bottom of the Rincón de Parangueo Maar (Guanajuato, México) and its probable relation with subsidence faults at Salamanca and Celaya, Boletín de la Sociedad Geológica Mexicana, 65, 169-188, 2013.

Barrientos, B., Cerca, M., García-Márquez, J., and HernándezBernal, C.: Three-dimensional displacement fields measured in a deforming granular-media surface by conbined frige projection and speckle photography, J. Opt. A-Pure Appl. Op., 10, 10 pp., 2008.

Cerca, M., Carreón-Freyre, D., Aranda-Gómez, J. J., and RochaTreviño, L.: GPR profiles for characterizing subsidence deformation in lake sediments within a mar crater, 15th International Conference on Ground Penetrating Radar GPR2014, Brussels, Belgium, 30 June-4 July, 4 pp., 2014.

Escolero-Fuentes, O. A. and Alcocer-Durand, J.: Desecación de los lagos cráter del Valle de Santiago, Guanajuato, in: El agua en México vista desde la Academia, edited by: Jiménez, B., Marín, L., Morán, D., Escolero, O., and Alcocer, J., Academia Mexicana de Ciencias, México, D.F., 99-116, 2004.

Kienel, U., Wulf Bowen, S., Byrne, R., Park, J., Böhnel, H., Dulski, P., Luhr, J. F., Siebert, L., Haug, G. H., and Negendank, J. F. W.: First lacustrine varve chronologies from Mexico: impact of droughts, ENSO and human activity since AD 1840 as recorded in maar sediments from Valle de Santiago, J. Paleolimnol., 42, 587-609, doi:10.1007/s10933-009-9307-x, 2009.

Lorenz, V.: On the growth of maars and diatremes and its relevance to the formation of tuff rings, B. Volcanol., 48, 265-274, 1986.

Pirrung, M., Büchel, G., Lorenz, V., and Treutler, H.-C.: Posteruptive development of teh Ukinrek East Maar since its eruption in 1977 A.D. in the periglacial area of south-west Alaska, Sedimentology, 55, 305-334, 2008.

Suhr, P., Goth, K., Lorenz, V., and Suhr, S.: Long lasting subsidence and deformation in and above maar-diatreme volcanoes - a never ending story, Z. Dtsch. Ges. Geowiss., 157, 491-511, 2006. 